\title{
Biomedical waste management: Health and safety practices and extent of its use by waste handling workers
}

\author{
SWATI SRIVASTAVA* AND RITU SINGHVI \\ Department of Family Resource Management, Maharana Pratap University of Agriculture and Technology, \\ UDAIPUR (RAJASTHAN) INDIA
}

\begin{abstract}
Biomedical waste management has recently emerged as an issue of major concern not only to hospitals, nursing home authorities but also to the environmental and law enforcement agencies, media and the general public. The present investigation was conducted in Udaipur city of Rajasthan state to know the health and safety practices and extent of its use by 255 waste handling workers in one government hospital,two private hospitals and common treatment facility. The health and safety measures used by waste handling workersas found that they were adopting most of these two practices always as per the biomedical waste (Management and Handling) Rules,1998. Only among few waste handling workers was sometimes not followed these health and safety measures during handling of biomedical waste. It was basically due to un-awareness of health hazards which may occur because of improper training related to the biomedical waste management practices.
\end{abstract}

Key Words : Biomedical waste, Safety measures, Waste handling workers

View point paper : Srivastava, Swati and Singhvi, Ritu (2016). Biomedical waste management: Health and safety practices and extent of its use by waste handling workers. Asian Sci., 11 (2): 117-120, DOI : 10.15740/HAS/AS/11.2/117-120.

\footnotetext{
* Author for correspondence

Swati Srivastava, Department of Family Resource Management, Maharana Pratap University of Agriculture and Technology, UDAIPUR (RAJASTHAN) INDIA (Email: swati9101990@gmail.com)
} 